\title{
Writing a Videogame: Rhetoric, Revision, and Reflection
}

\author{
Kendall Gerdes, Melissa Beal, and Sean Cain* \\ $10 / 1 / 2020^{\dagger}$
}

\begin{abstract}
This essay reflects on a three-part assignment in which students plan, design, and reflect on a text-based videogame. Created originally for a composition course focused on rhetoric and videogames, the assignment lends itself to teaching about the writing process, especially invention and revision, teaching procedural rhetorics, and teaching technical communication concepts such as iterative design and usability. This essay is coauthored by the instructor with two students who took the course in different semesters, highlighting the collaborative nature of even solo-authored game design, as well as how making games can help students take up rhetorical concerns in other genres.
\end{abstract}

\section{Reflective Description and Course Context}

\section{Dr. Kendall Gerdes}

At Texas Tech University, ENGL 4360 is an advanced topics course formally called "Studies in Composition." For three semesters, I had a chance to teach this course under the title "Weird Videogames" in the Department of English's Technical Communication program. The course focuses on games that are "weird" in that they push back against a widely held view of videogames as technical challenges, best left to a small group of expert designers and players - instead, the games we play emphasize culture, critique, and collaboration. ${ }^{1}$ Yes, students get to play videogames in class, and for homework, and in the final unit of the course, they also design their own playable videogame. The assignment to "write" a text-based videogame is the focus of this essay, including the

\footnotetext{
*University of Utah, kendall.gerdes@utah.edu; Texas Tech University, melissa.g.beal@gmail.com; Texas Tech University, sean.cain@ttu.edu. Copyright 2020 Kendall Gerdes, Melissa Beal, and Sean Cain. This work is licensed under a Creative Commons Attribution-NonCommercial 4.0 International License (http://creativecommons.org/licenses/by-nc/4.0/).

${ }^{\dagger}$ Submitted, 5/23/2019; Accepted, 4/13/2020.
} 
planning document for the game, the game itself, and the reflection students write after they submit their game's final version.

ENGL 4360 usually enrolls juniors and seniors, often (though not always) working on a major or minor in English or a program in the Department of English, such as Technical Communication. Substantial writing is required. Because the course is writing-focused, the readings and writing assignments are organized around the rhetorical issues that videogames raise: What do the rules encourage me to do (or not do)? How does the game get me to identify myself with the player-character? What arguments does the game itself make? ${ }^{2}$ This "writing a videogame" assignment could be used in a variety of rhetoric, writing, and technical communication courses to teach concepts including revision, procedural rhetoric, iterative design, and usability.

The first semester I taught Weird Videogames, the class met once a week and had short weekly writing assignments, but in the second and third semesters, departmental scheduling needs changed the class meetings to twice weekly, and I combined some assignments to make longer but less frequent writing assignments. However, I retained the structure of the final unit, a three-part assignment in which students plan, design, and reflect on their own text-based videogame. Before they get to this final project, students in "Weird Videogames" will have written a game review, followed by a rhetorical analysis of a game. They begin the final assignment by writing a Game Prospectus, a short plan that identifies characters, storylines, and design elements that students hope to include. Students then have a week's worth of class time to work on their game with their peers in a "game jam" setting, helping each other solve design problems in an unstructured collaborative environment. After students submit their game (which is turned in as an HTML file), the last component of the assignment is an Author's Statement, in which students reflect on their game design choices and rhetorically analyze the final version of their game.

Throughout the semester, students in the course play assigned videogames each week, sometimes for homework and sometimes in class - or even as a class. Discussions are organized around getting students to think rhetorically about videogames. What audience is this game for? What beliefs does it want that audience to identify with? What rules structure the game, and how do those procedures shape the things that players are supposed to value or pursue? Because students in my courses are evaluated using a portfolio grading method called the Learning Record, ${ }^{3}$ they often write about their answers to these questions in weekly journal entries. (Students eventually use the journal as evidence in a final essay assigning themselves a grade for the course.) In designing their own videogames, students draw on the models they have been assigned to play in class, and they are expected to apply the rhetorical principles they have studied to their own game's design. The final reflection allows students the opportunity to make these influences and aims explicit, as well as to analyze any changes in their plans that evolved out of the design work itself. The semester ends with an in-class arcade in which students play each other's games and offer feedback that helps authors compose their final reflections. 
One aim I had in crafting this assignment was to get students to see rhetoric as both critical and productive: in addition to writing about and commenting on games, I also wanted students to experience the rhetorical work of writing a game itself. I also wanted this assignment to demystify the composing process of making games. Imagining that my students for the most part would relate to videogames as consumers (whether highly engaged or alienated, or somewhere in between), I wanted them to take on the role of videogame designers, too. As I argue in the next section, there are plenty of reasons to make games other than commercial success, and I wanted my students to try out the possibilities that writing videogames can afford.

\section{Teaching with Twine: Game Jams and Collaborative Learning}

The platform we used to design our videogames is an open-source software program called Twine, first created in 2009 by Chris Klimas; for more on how Twine and Twine games have been used in other types of courses, see Salter (2015); Hergenrader (2016); Thevenin (2017); Milligan (2019); and more at twinery.org/wiki/twine:education. Two documents were especially influential in developing this assignment, and they both fall somewhere between technical documentation and manifesto: they focus both on how to use Twine to make games as well as on why you might want to make games. Students read the first text, Porpentine's (2012) "Creation Under Capitalism and the Twine Revolution," before their first in-class game jam. "Creation Under Capitalism," which was published as a blogpost to the site Nightmare Mode in November 2012, opens with this robust claim about the power of digital games:

Our global network is composed of human minds uploaded into word form.

On this plane the word is the most potent unit of force.

It costs a couple of keystrokes to control someone else's brain for a second, and longer if you do it right. (para. 1-3)

After reviewing the contentious history of interactive fiction, hypertext, and digital games, Porpentine explains the damage wrought by corporate game studios who make games for exclusive, expensive, and tightly monitored platforms. Corporate games position their audience as consumers, not creators. Because their aim is to sell the most copies, corporate games tend to reproduce the all normative privileges of the world outside of games, with its racist, sexist, homophobic, ableist, and transphobic values. Porpentine argues that Twine can help ordinary people connect with their creativity by making hypertext games and sharing them in order to connect with a community. Making games outside of the gatekept corporate games industry can reclaim creativity as a means of resistance to capitalism.

The other text that inspired this assignment is Anna Anthropy's (2015) "Love, Twine, and the End of the World," published as a choose-your-own-adventure-style chapter in The State of Play: Creators and Critics on Videogame Culture. Anthropy argues 
that making Twine games is akin to doodling on napkins or keeping a journal - she writes that even "people who don't think of themselves as artists" (Section 4) can both casually and meaningfully engage in artistic activity. Reflecting on her own experiences making Twine games, Anthropy explains how composing games can help people navigate challenging life choices, share personal experiences with others, and even heal from past traumas. Anthropy's chapter closes with this direct address to readers, urging us to make games as a way of connecting with others: "You spent a lifetime sending out signals you were scared would be misinterpreted, misunderstood, garbled, absorbed, allowed to pass unregistered into the cold of space. Now you know. The signal was never lost" (Section 15). Anthropy emphasizes the creative spark ignited by making games collaboratively by working at the same time or responding to a single theme in what is called a game jam.

Having students make videogames in a classroom game jam enables them to learn Twine's procedures quickly, sharing pointers and solving problems together as they write. "Game jam" is an industry term for creating a videogame in a limited, usually short, amount of time. The idea is to bring an idea to completion quickly; once a game exists, it can always be improved or remade later. Game jams are typically done with a team or in the presence of peers. The collaborative environment encourages students to research as a group and to share insights and information; students can solve problems much more quickly in a game jam than in an isolated study space. Students can submit their games as HTML files simply by attaching the file to an email, or uploading it to a shared folder, but they can also publish their Twine games online through the free Twine hosting site philome.la. ${ }^{4}$ For more about the features of Twine that make it well-suited for creating independent and personal games, see Friedhoff (2014); for examples of such games, see Kopas (2015).

\section{Student Reflections: Planning, Writing, and Reflecting on Twine Games}

In this section, article coauthors Melissa Beal and Sean Cain, students who both took the Weird Videogames course with me in separate semesters, share their reflections on completing the Writing a Videogame assignment. Melissa and Sean are both graduates of the Department of English programs in Technical Communication and Creative Writing.

The supplementary files for this article include Melissa's and Sean's sample Game Prospectuses and Author's Statements, as well as their sample Twine games, available online at philome.la/Redpression and at philome.la/Secain95.

\section{Melissa Beal}

The prospect of creating a game inspired me, as it is a way to create fiction that people can interact with. I used the Game Prospectus assignment to create a framework that organized my thoughts on the story and helped me pinpoint where applying rhetorical techniques would be most effective.

In my game "War Memories," I specifically focused on how war is cruel, but is something 
to be remembered, not forgotten. Rhetorically, my main focus was identification. I wanted players to experience the game as the player-character, experiencing the trauma personally. I wrote my Author's Statement for the purpose of analyzing and discussing the different rhetorical techniques I used to encourage identification. The techniques that I discuss in the Author's Statement include giving players the option to study the protagonist's room and my use of glitched text, which looks like like thijis is In my Author's Statement, I explain my use of glitched text by saying that the "glitchy words are meant to be a visual representation of the protagonist's struggle to remember. Because the player can actually see these struggles instead of just reading about them, it should be easier for them to understand the protagonist's suffering." I also pushed a player's identification with non-player characters (or NPCs) by having them spend time with NPCs and putting them in full control of which NPCs live or die during the course of the game. I end the game with a quote by William Tecumseh Sherman that I felt summed up my message: "War is cruelty. There is no use trying to reform it." This quote was added in to communicate my message to players one last time.

While the Author's Statement was an effective way to analyze my own game, the Game Jam was a great way to see to see other students' techniques and creations. I find that the Game Jam was especially interesting in the context of a hybrid course ${ }^{5}$ by sharing our games online, all students were given the chance to connect with and learn from others. It was possible to sit next to the creator of a game you were playing, but you might also play games made by a classmate across the state or country. On top of the excitement of interactivity, I was able to receive feedback from other students on bugs in my game or extra things that I could add. Giving and receiving feedback on games taught me how to create a better player experience and how to communicate my ideas well.

This course was the second course that I took on rhetoric; I took the first during the same semester, and it was more traditional: students were given readings that explained how rhetorical tools were used in speech and writing. As the semester progressed, we analyzed a handful of speeches and writings. While that class was beneficial, I felt that studying rhetoric in videogames helped me understand the topic better. Similar to the first class, I was given ample examples of how rhetorical devices were used and to what end. However, there was no overt vocabulary study as there was in the other class. Instead, students were encouraged to understand rhetoric through real world examples by interacting with videogames as much as possible. The opportunity to apply those devices on our own only further cemented the rhetorical ideas that were taught in class, as not only did we study them and understand them, we were also invited to use them. In my own experience, being able to apply and not just observe rhetorical techniques has been more helpful, especially in the long term, than more traditional study.

\section{Sean Cain}

Since starting college, I had an interest in writing horror. I entered the class with an idea I had trouble finding a form for: a story in which someone possesses a device called 
the "reality check" that allows them to momentarily see "true reality." As it turns out, "true reality" is filled with horrifying, previously invisible, monsters. I wanted to express this existential fear that monsters might be roaming about in places we consider safe or mundane. When we got to the Twine game portion of the class, I realized a Twine game was the perfect medium for this story. The monster is one that bends reality itself, so the player has to think outside the box when interacting with it. The mechanic of reader choice allowed my story to go in a special direction.

In my game, "The Black Pages," the player is experiencing financial trouble. They happen upon a website called The Black Pages, a site where people can list jobs for paranormal investigations. The player encounters a high-paying job: to investigate a supposedly haunted and abandoned apartment complex. Thinking it will be easy money, the player accepts, and purchases the "reality check" required for the job. Once the player gets to their destination and uses the reality check, it reveals a monster dubbed "the Seer." A tall and scrawny pale humanoid with no features save for thousands of tiny black dots covering its body which, upon further inspection, are tiny eyes looking in every direction. This creature has the ability to alter perception to such an extent that it changes reality (at least on an individual basis).

From there, the game allows players to choose between specific philosophies regarding the best way to deal with this monster. If the player feels the Seer is pure evil and should not be a part of this world, they have the option to kill it, but they sacrifice the ability to capture evidence of it and therefore lose out on getting paid for the job. If the player prefers to be an observer, or is more concerned with completing the job, they can simply capture evidence of the Seer and then make their escape leaving the monster alive but completing the job. Then, once they have the evidence, they can choose to hand it over to the person who employed them, receiving payment, or they can reveal the evidence to the world causing a revolution in the understanding of reality. However, the player is assassinated at the end of that path. My intention with each path was to capture each ethical conclusion a player might reasonably draw about such a creature. What should someone do if they encounter such a creature? What should someone do with the proof of its existence?

Expressing this idea with multiple paths was a fortunate blessing; had I written this story as a standard narrative with one ending, I do not think it would have reached its full potential. The restraints of one path within one story can sometimes feel paralyzing; the creative freedom of this project and the branching playstyle of Twine allowed me to make it into something new and unique. It also makes Twine projects more exhaustive and more time consuming than linear fiction writing, which is why the Game Prospectus aided my development of the project. The goal of the Game Prospectus assignment was to define the meaning/message of my game as well as how I planned to accomplish that message. Writing fiction is often an intuitive process, and the Game Prospectus took some of the intuition out of the equation. This helped me see fiction as more of a rhetorical process: I have an end argument I want to achieve, but how do I get there? This was different than my usual approach, and while I do not think this approach is 
necessary to creative writing, I do think it was a useful one.

The lesson rounded out with an Author's Statement that provided a satisfying end to the project; it gave me a space to explain my reasoning behind certain choices and sacrifices. The Author's Statement was similar to the Game Prospectus but more reflective than prospective. It was an introspective look back on the choices I made, how the final product differed from my vision, and the changes I made in revision. My original plan was far more ambitious than what was actually made, which I think is common for creative projects, but being able to rationalize and justify whatever shortcomings my final project encountered gave me a sense of accomplishment and a potential path to realize my original vision with more time.

\section{Conclusion}

\section{Dr. Kendall Gerdes}

As my coauthors demonstrate above, students learned a great deal about writing in multiple genres from the Writing a Videogame sequence. A central argument this article aims to advance is that making videogames is a writing activity. Many of the composing processes that we want our students to learn can be practiced by making videogames. As the instructor, I think one of the biggest successes of this assignment happens when students can realize their own creative freedom, like Melissa and Sean did. And as their instructor, I also get to observe how students connect the processes of planning, writing, revising, and reflecting to the rhetorical concerns and objectives. Students strategize and learn techniques from each other about how best to realize their goals. They think constantly about their audience - their games' players - and whether they successfully communicated what they set out to communicate. They think of more ideas than they could possibly write in the final weeks of the course, so they learn to bring their projects to a close to meet a deadline, thinking about the possible future iterations of games they might keep working on.

Instructors may read this essay and still fear that making videogames is too complicated a task for them to lead their students in. It is true that the intimidation students might feel when they learn they will make their own videogames can be intense. But Twine's simplicity and accessibility mean that students and instructors alike can learn it quickly and do not need any specialized knowledge of computer code to write their own videogames. I encourage instructors to consider how their own course goals might be served by having students complete this assignment sequence in full or even just in part: taking just one class period to have students make playable games with Twine can help them think about the choices they make as writers and the effect of those choices on their readers - and the endless horizon of possibilities that they, as writers, could choose to explore. 


\section{Assignment: Game Design Prospectus and Author's Reflection}

(To view a PDF facsimile of the original formatting of this assignment, return to this article's homepage and locate the link to the "Assignment" PDF.)

Spring 2018

\section{Game Prospectus Assignment (4/18/2018)}

In your journals, write a game prospectus-a proposal for the Twine game you'll submit as a final project.

Think about the argument you want your game to make. How can you design procedures to reflect that? To enable/constrain your players? Also consider:

- Who are the characters in your game? How much can players customize them?

- What's the storyline like? Are there branches? Multiple endings?

- Think about the kinds of links players will interact with: what words or phrases do players click on? Are they highly descriptive, or are their effects hidden at first?

- What will design elements contribute to your game? Are fonts, text colors, and background colors important? Will you incorporate images? Sounds?

You'll have next week in class to work on your Twine game, and we'll have a Twine Arcade on April 30, so think about scope: what will you actually be able to accomplish/finish in that amount of time?

\section{Author's Statement Assignment (4/30/2018)}

Your Twine game is the last major project in our course before the LR Final. When you write about your game on the LR Final, you'll have three other components to draw on:

- Your game prospectus

- Your author's statement

- A review of your game from a peer

For your author's statement, think about an artist's statement that might accompany a piece in a museum. You can use your prospectus as a draft if you like, but in any case you should revisit it and discuss how you realized (or changed) your plans along the way. Consider also:

- What did you hope to argue?

- What audience did you hope to reach?

- What beliefs or emotions does your game appeal to? 
- What do the procedures of your game make possible (or impossible)?

You may also discuss how characters, storyline(s), ending(s), and design decisions you created shape your game. Submit your author's statement on Dropbox before class on Wednesday, $5 / 2$ !

Fall 2017

- Game Prospectus. Propose your own videogame! This short should outline your plans for a game you will make in Twine. Who are your characters? What is your storyline? How will your game end?

- Author's Statement. This short will accompany your Twine game (think artist's statement, like might accompany a piece in a museum). What did you hope to argue? What beliefs or ideologic did you appeal to? How did you aim to garner assent from players? What does your game demonstrate about rhetorical identification?

\section{Notes}

\footnotetext{
${ }^{1}$ The course title was intended to signal to students that we would be covering mostly non-mainstream videogames, where "weird" functions a bit euphemistically to name games that dealt with a range of potentially controversial topics, including queer relationships, mental health, immigration enforcement, gun violence, and childhood trauma.

${ }^{2}$ These questions have been taken up by scholars in games studies as well as rhetoric, writing studies, and technical communication. For more on procedural rhetoric, see Bogost (2007); King (2010); Ruberg (2015); Holmes (2017); on videogames and identification, see Shaw (2012); Warren (2013); and on the inventiveness of indie games, see Keogh (2019).

${ }^{3}$ The Learning Record method of assessment was adapted to higher education by M.A. Syverson; for more info, see learningrecord.org.

${ }^{4}$ Philome.la closed to new submissions at the end of September 2019.

5 "Hybrid" here refers to a course that enrolls both onsite and online students, and the whole class meets synchronously with some students in the classroom and some using videoconference software.
}

\section{References}

Anthropy, A. (2015). Love, Twine, and the End of the World. In D. Goldberg \& L. Larsson (Eds.), The State of Play: Creators and Critics on Videogame Culture (pp. 
31-51). New York, NY: Seven Stories Press.

Bogost, I. (2007). Persuasive Games. Cambridge, MA: The Massachusetts Institute of Technology Press.

Friedhoff, J. (2014). Untangling Twine: A Platform Study. In C. Pearce, J. Sharp, \& H. Kennedy (Eds.), Proceedings of DiGRA 2013: DeFragging Game Studies. Digital Games Research Association DiGRA.

Hergenrader, T. (2016). The Place of Videogames in the Digital Humanities. On the Horizon, 24 (1), 29-33.

Holmes, S. (2017). The Rhetoric of Videogames as Embodied Practice: Procedural Habits. London: Routledge.

Keogh, B. (2019). Between Triple-A, Indie, Casual, and DIY. In K. Oakley \& J. O'Connor (Eds.), The Routledge Companion to the Cultural Industries (pp. 152-162).

King, M. (2010). Procedural Rhetorics-Rhetoric's Procedures: Rhetorical Peaks and What It Means to Win the Game. Currents in Electronic Literacy. Retrieved from https:// currents.dwrl.utexas.edu/2010/king_procedural_rhetorics_rhetorics_procedures.html

Kopas, M. (Ed.). (2015). Videogames for Humans: Twine Authors in Conversation. New York: Instar Books.

Milligan, C. A. (2019). Immanent Interbodies: Composing Disability through Embodied Choragraphy. Computers and Composition, 53, 75-85.

Porpentine. (2012). Creation Under Capitalism and the Twine Revolution. Retrieved from https://web.archive.org/web/20131114013954/http://nightmaremode.net/2012/11/ creation-under-capitalism-23422/

Ruberg, B. (2015). No Fun: The Queer Potential of Video Games That Annoy, Anger, Disappoint, Sadden, and Hurt. QED: A Journal in GLBTQ Worldmaking, 2(2), 108-124.

Salter, A. (2015). Learning Through Making: Notes on Teaching Interactive Narrative. Syllabus, 4(1).

Shaw, A. (2012). Do You Identify as a Gamer? Gender, Race, Sexuality, and Gamer Identity. New Media \& Society, 14(1), 28-44.

Thevenin, B. (2017). Twine as Alternative Media: Video Games, the Culture Industry and Social Change. Teaching Media Quarterly, 5(2).

Warren, K. (2013). Who Are You Here? The Avatar and the Other in Video Game Avatars. In R. Colby, S. Johnson, \& R. Colby (Eds.), Rhetoric/Composition/Play through Video Games (pp. 33-43). New York, NY: Springer. 